\title{
Numerical Analysis of the Adiabatic and Quasi Steady Model of Free Piston Stirling Engine
}

\author{
Ayodeji Sowale and Athanasios J. Kolios \\ Offshore Renewable Energy Engineering Centre, School of Water, Energy and Environment, Whittle Building 52, Cranfield University, \\ Bedfordshire MK43 0AL
}

\begin{abstract}
This study presents the numerical simulation of the adiabatic and Quasi steady models of the free piston Stirling engine, the mathematical equations are presented, and design parameters are determined and used as input for the simulation. The simulations are computed under adiabatic and Quasi operating conditions, and their output results are compared. The similarities and differences in the model predictions in terms of the pressure to volume diagram, the amplitudes of the pistons and displacer, temperature, efficiency, power output and stable operation are observed and investigated. The models are validated against the experimental output and the results show a good agreement with the experiment. The adiabatic model predicted an output power of $862 \mathrm{~W}$, while Quasi steady model predicted more accurate output power of $997 \mathrm{~W}$ at frequency of $30 \mathrm{~Hz}$ in relation to the $1000 \mathrm{~W}$ of the experimental output. The effects of the variation of engine's parameters on the output power are also observed and presented.
\end{abstract}

\section{Introduction}

In recent years the consumption of energy and environmental pollution has been a major issue of controversy. The rapid increase in the cost of supply of energy and the continuous increase in environmental and noise pollution, have resulted to investigations into substitute machines that converts energy in the form of thermal, electrical or pressure to mechanical form. The free piston Stirling engine (FPSE) was introduced by Willian Beale in 1964. It is an external combustion engine with no mechanical linkage of the oscillatory components [1]. The disadvantage of the FPSE is the lack of rotating shaft, the engine uses springs and dampers in the oscillatory movements during operation, which can act as a hindrance in the stability and effective modelling of the FPSE. Therefore, accurate description and calculation is required to determine the operational performance and achieve a steady operation of the engine. Recent investigations have been conducted on the thermodynamic analysis of the free piston Stirling engine. Various approach have been carried out on the numerical model of first and second order models of the FPSE. A study was conducted by Formosa and Frechetter [2] on the scaling effects on the FPSE taking into consideration the heat exchangers geometry and the masses of the displacer and piston in relation to the heat losses in the engine. The output results showed that the indicated output power and efficiency of the miniaturized FPSE can be determined using the stipulated method. Begota et al [3] evaluated the stability analysis of the FPSE using the dynamic and thermodynamic method by employing the eigen values of state matrix and the model showed a good agreement with the experimental output. Riofrio et al [4] presented a dynamic model using the linear control method to design the FPSE to determine the stability of the engine. The influence of the temperature and damping load on the engine output was also observed and presented. Sowale [5] developed a numerical analysis of the Quasi, isothermal and adiabatic model of the FPSE by solving the motion equations of the displacer and piston simultaneously with the thermodynamic equations to determine the output performance of the engine. The results showed a good agreement with the experimental output. A mathematical model of the FPSE was developed by Jia et al [6] where the features of the pistons and displacer were defined including their natural frequency. The outputs showed the system was under forced excitation by varying the damping coefficient and spring stiffness. The piston and displacer's velocity and amplitude plotted against each other, formed a convergence which indicated the stable operation of the engine. Yang et al [7] developed thermodynamic analysis of a modified FPSE using the thermoacoustic theory. The results presented a good thermodynamic performance compared to the developed prototype. A numerical model of the FPSE was developed by Kim et al [8] to investigate the effects of the combustion phase on the motions of the displacer and piston. The output performance showed various spark timing for the piston velocity can be determined using efficiency conversion to work from combustion.

In this study, the adiabatic and Quasi steady model of the FPSE under the similar operating condition is 
presented and results analysed to compare the performance of the two models. MATLAB is used to predict the performance of the free piston Stirling engine, where the characteristics of the engine are described by the linear dynamics theory. The modelling of the free piston Stirling engine requires an accurate dynamic equation of motion for the piston and displacer to predict the engine's performance. The analysis of the equations of motion for both the piston and displacer are solved in terms of the damping and stiffness coefficients of the engine. The aim of this paper is to predict the operating conditions of the FPSE at steady state and to generate the power output of $1 \mathrm{~kW}$. The numerical models are validated with experimental data of the Sunpower Re1000 free piston Stirling engine prototype. The results of the output obtained from the proposed model using the standard description of the engine gives a close result to the experimental output.

\section{Mechanism of FPSE}

The mechanism of the FPSE is shown in Fig. 1. The engine consists of a displacer and piston, mechanical springs and dampers for both the displacer and piston and the engine casing. There is no mechanical linkage between the piston and displacer like the kinematic Stirling engines, the mechanical springs connect the displacer and piston the engine casing. The dampers act as an additional load to the piston and displace and they also helps to reduce vibration during oscillation. The pressure from the working gas volume in the engine acts on the piston and displacer and subject them to oscillatory motion in their cylinders. The displacer is designed to have a low mass compared to the piston so as to maintain necessary phase angle and produce more effective output. The working volume is made up of the expansion and compression spaces volume, and heat exchangers volume including hot, regenerative and cold volume. The working gas passes through a heating, regeneration and cooling process in the heat exchangers chambers.

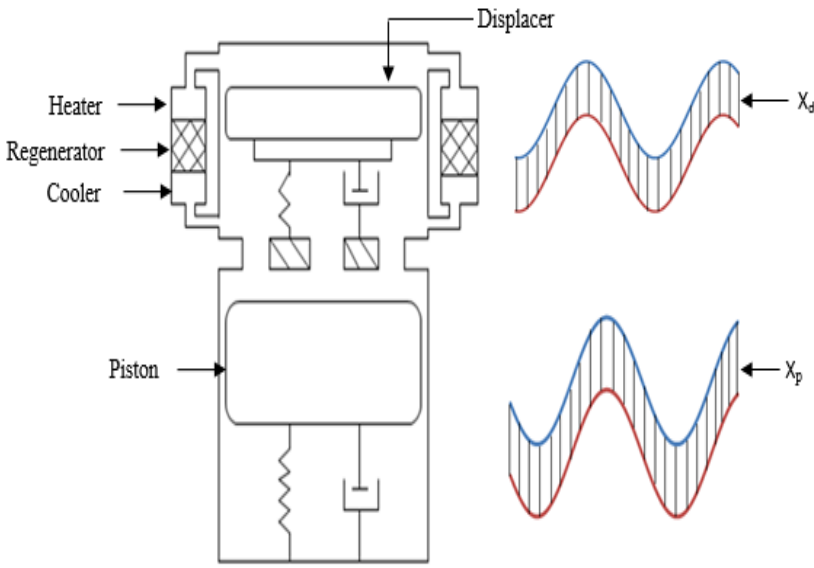

Figure 1. The oscillation of piston and displacer in correspondence with the position of the piston and displacer in the engine during operation.[5]

\section{Methodology}

The numerical model of the adiabatic and Quasi steady of the FPSE are developed in MATLAB program. The adiabatic was modelled under the adiabatic condition of the working fluid temperature within the walls of the expansion and compression space. The Pressure, volume and temperatures of the work spaces and heat exchangers were determined by making them functions of each parameter and was computed over the cycle until steady state was achieved. The Quasi steady model takes into consideration more details on the thermodynamic performance of the FPSE including the thermal losses, pressure drops. The operating conditions and assumptions were stated for the models. Input parameters used are that of the Sunpower RE-1000 FPSE and is presented in Table 1 .

\subsection{Assumptions for the ideal adiabatic model}

- The total mass of gas in the engine is constant.

- There is no pressure drop in channels of the engine.

- The engine operates at steady state condition.

- The gas is an ideal gas.

- The spring's masses are not considered.

- The springs in the engine are linear.

- The motion of the engine casing is neglected.

\subsection{Assumptions for the Quasi steady model.}

The assumptions for the general operating conditions of the numerical models were determined and are stated below:

- The working volume pressure and block pressure is equal when the engine is in static equilibrium.

- The temperatures of the surrounding walls of the working gas volume changes with time.

- The masses of the piston and displacer springs are not considered.

- The springs are positioned in a linear order.

- No leakage is expected to occur between the mechanical components of the engine.

- The working fluid is an ideal gas.

- To maintain the required phase angle between the displacements of the moving elements the mass of the displacer is lighter than the piston.

- The regenerator temperature is required to be equal to the average of the cooler and heater temperature.

- The engine block is stationary.

The flow chart of the numerical procedure of the simulation of the FPSE is presented in Fig. 2. 


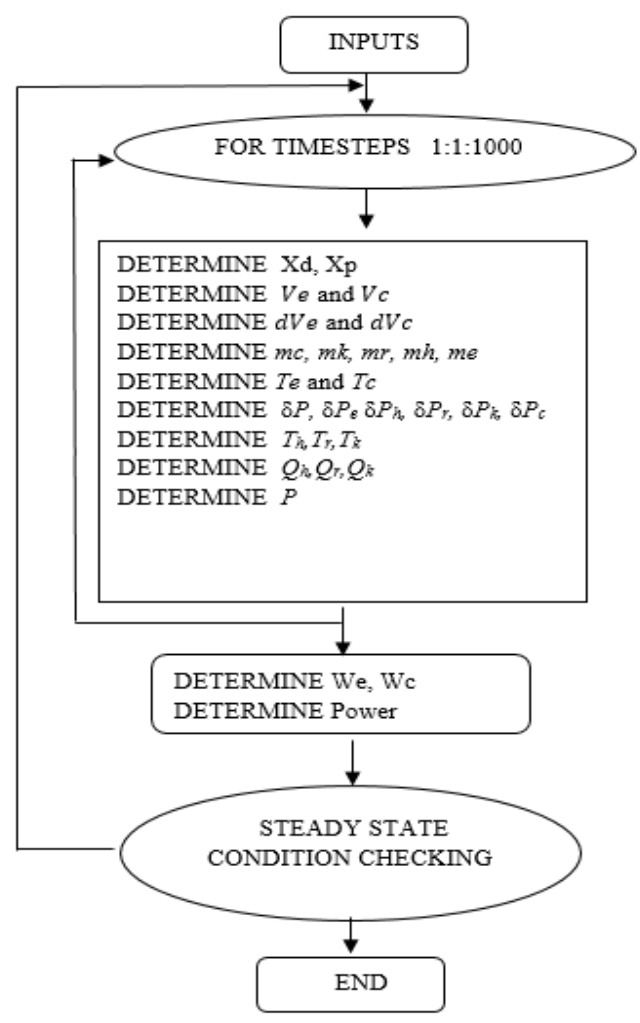

Figure 2. Flow chart of the numerical procedure

\subsection{Equations used in the mathematical model}

\subsubsection{Generalized analysis}

To describe the action of a free piston Stirling engine, it is essential to assume the harmonic motion of the displacer and piston. There are three forces that are applied during the operation, they are; applied force (force from the pressure of the working gas), spring force and damping force [9]. The equations of motion for both the piston and displacer are simplified to determine the operation of the engine. The outputs generated by the engine are the temperature, pressure, displacements and velocity of the displacer and piston. Using the Newton's second law that is employed to describe the motion of the piston and the displacer, it states:

$$
\begin{gathered}
\sum F=m \bar{x} \\
F+F_{\text {damping }}+F_{\text {spring }}=M \bar{x}
\end{gathered}
$$

The motion of the displacer is a result of the spring force, damping force, area of the displacer and the pressure of the working fluid.

$$
m_{d} \bar{x}+K_{d} x_{d}+C_{d} \dot{x}=P\left(A_{d}\right)
$$

Where $m_{d}$ is the mass of the displacer. $K_{d}$ displacer spring constant. $C_{d}$ displacer damping constant. $A_{d}$ cross sectional area of the displacer. The motion of the piston is a result of the damping force, spring force, area of piston, the bounce space pressure and the pressure of the working fluid.

$$
m_{p} \bar{x}+K_{p} x_{p}+C_{p} \dot{x}=A_{p}\left(P-P_{b}\right)
$$

Where $m_{p}$ is the mass of the piston. $K_{p}$ piston spring constant $C_{p}$ piston damping constant. $A_{p}$ cross sectional area of the piston. $P_{b}$ bounce space pressure. The equation for pressure in the engine for a closed cycle operation [1].

$$
P=\frac{M R}{\left(\frac{V c}{T c k}+\frac{V k}{T k}+\frac{V r}{T r}+\frac{V h}{T h}+\frac{V s}{T h s}\right)}
$$

Boundary conditions for the conditional temperatures If $m_{c k}{ }^{\prime}>0$ then $T_{c k}=T_{c}$ else $T_{c k}=T_{k} \quad$ If $m_{h e}{ }^{\prime}>0$ then $T_{h e}=T_{h}$ else $T_{h e}=T_{e}$

From the engine's geometry the positions of the piston and displacer $x_{p}$ and $x_{d}$ with the expansion and compression volumes $V e$ and $V c$ can be derived from the following equations:

$$
\begin{gathered}
V e=\left(V_{\text {cle }}+x_{d}\right) A_{d} \\
V c=\left(V_{\text {cle }}+x_{p}\right) A_{p}-\left(x_{d}+V_{\text {cle }}\right) A_{d}
\end{gathered}
$$

Where $V_{\text {cle }}$ and $V_{\text {cle }}$ are the expansion and compression space clearance volumes. By differentiating $V e$ and $V c$ above the new equations resulted to

$$
\begin{gathered}
d V e=\dot{x}\left(A_{d}\right) \\
d V c=\dot{x}\left(A_{p}\right)-\dot{x}\left(A_{d}\right)
\end{gathered}
$$

The momentum equation for the displacer

$$
m_{d} \ddot{x}_{d}+K_{d} x_{d}+C_{d} x_{d}=P\left(A_{d}\right)
$$

The momentum equation for the piston

$$
m_{p} \ddot{x}_{p}+K_{p} x_{p}+C_{p} \dot{x}_{p}=A_{p}\left(P-P_{b}\right)
$$

Work done in compression space and expansion spaces are

$$
\frac{d W_{\varepsilon}}{d t}=P_{c} \frac{d V_{\varepsilon}}{d t} ; \frac{d W_{Q}}{d t}=P_{\Theta} \frac{d V_{Q}}{d t}
$$

The indicated work in the cycle is

$$
W_{i n}=\int_{0}^{t}\left(P_{e} \frac{d V_{v}}{d t}+P_{c} \frac{d V_{c}}{d t}\right)
$$

The indicated power of the engine is

$$
P_{\text {in }}=W_{i n} f
$$

\subsection{Procedure for generalized simulation}

MATLAB was employed to write the codes for the numerical simulation using the mathematical equations above. The initial input parameters for the engine are determined at the beginning of the program, some which are variable and constant. The working process of the FPSE is analysed using the mathematical equations listed above. The initial values of both the variable and constant parameters were defined, such as; the positions of the displacer and piston, the working spaces and heat exchangers temperature, then the equations of the motions of the piston and displacer are simplified using Runge-Kutta (rk4) solver in MATLAB that solves differential equations simultaneously using a trial step interval midpoints to remove errors in computation. For the Quasi model simulation, the initial values of the parameters are defined suh as; the temperatures of the heater and cooler, the dynamic pressure, positions of piston and displacer at equilibrium, the equations for pressure drop and thermal losses are determined. Also the initial temperature in the expansion and compression spaces are defined and Runge Kutta ( $\mathrm{rk} 4)$ was employed to solve all the equations using siimilar approach to the procedure in the adiabaic simulation. The simulation is then computed over 5 cycles in 1000 time steps to achieve steady state operation of the FPSE. 
Table 1. Parameters Of The Sunpower Re-1000 Fpse [1]

\begin{tabular}{|c|c|c|c|}
\hline Engine Data & Value & & Value \\
\hline General & & Geometric & \\
\hline $\begin{array}{l}\text { Mean } \\
\text { pressure }\end{array}$ & 70 bar & $\begin{array}{l}\text { Displacer frontal } \\
\text { Area }\end{array}$ & $0.018 \mathrm{~m}^{2}$ \\
\hline $\begin{array}{l}\text { Heater } \\
\text { temperature }\end{array}$ & $780 \mathrm{~K}$ & $\begin{array}{l}\text { Expansion space } \\
\text { clearance volume }\end{array}$ & $0.02 \mathrm{~m}^{3}$ \\
\hline $\begin{array}{l}\text { Cooler } \\
\text { temperature }\end{array}$ & $350 \mathrm{~K}$ & $\begin{array}{l}\text { Compression } \\
\text { space clearance } \\
\text { volume }\end{array}$ & $0.016 \mathrm{~m}^{3}$ \\
\hline $\begin{array}{l}\text { Oscillating } \\
\text { frequency }\end{array}$ & $30 \mathrm{~Hz}$ & Masses & \\
\hline Phase angle & $90^{\circ}$ & $\begin{array}{l}\text { Mass of the } \\
\text { piston }\end{array}$ & $6.2 \mathrm{~kg}$ \\
\hline Geometric & $0.054 \mathrm{~mm}^{3}$ & $\begin{array}{l}\text { Mass of the } \\
\text { displacer }\end{array}$ & $0.426 \mathrm{~kg}$ \\
\hline Dead volume & $0.016 \mathrm{~mm}^{3}$ & Dynamic & \\
\hline $\begin{array}{l}\text { Volume of } \\
\text { heater }\end{array}$ & $0.027 \mathrm{~mm}^{3}$ & $\begin{array}{l}\text { Piston spring } \\
\text { stiffness }\end{array}$ & $296000 \mathrm{~N} / \mathrm{m}$ \\
\hline $\begin{array}{l}\text { Volume of } \\
\text { regenerator }\end{array}$ & $0.011 \mathrm{~mm}^{3}$ & $\begin{array}{l}\text { Displacer spring } \\
\text { stiffness }\end{array}$ & $25000 \mathrm{~N} / \mathrm{m}$ \\
\hline $\begin{array}{l}\text { Volume of } \\
\text { cooler }\end{array}$ & $0.018 \mathrm{~m}^{2}$ & $\begin{array}{l}\text { Piston damping } \\
\text { load }\end{array}$ & $461.5 \mathrm{Nsm}^{-1}$ \\
\hline $\begin{array}{l}\text { Piston frontal } \\
\text { area }\end{array}$ & $0.018 \mathrm{~m}^{2}$ & $\begin{array}{l}\text { Displacer } \\
\text { damping load }\end{array}$ & $35.34 \mathrm{Nsm}^{-1}$ \\
\hline
\end{tabular}

\section{Results and Discussion}

The output performance of the adiabatic and Quasi steady model of the free piston Stirling engine is presented in Figs. 3 to 11 to illustrate the comparison of the adiabatic and Quasi models of the FPSE. Their performance outputs are analysed and discussed.

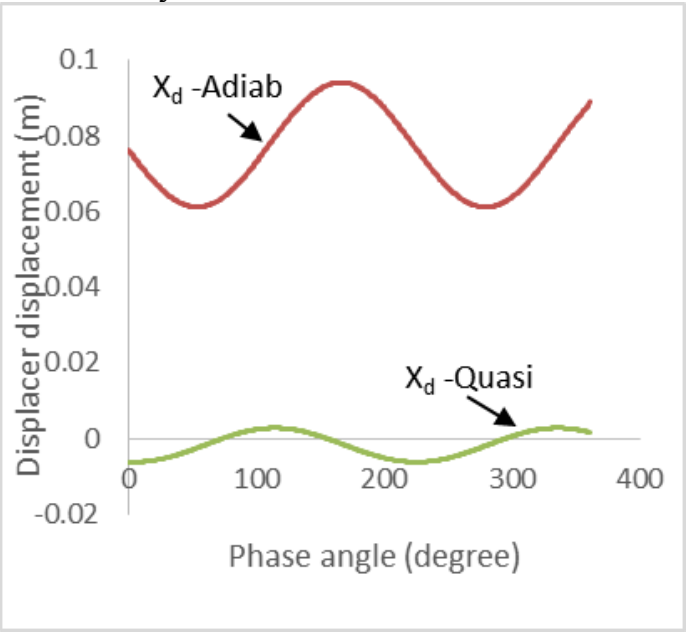

Figure 3. Displacer positions against phase angle

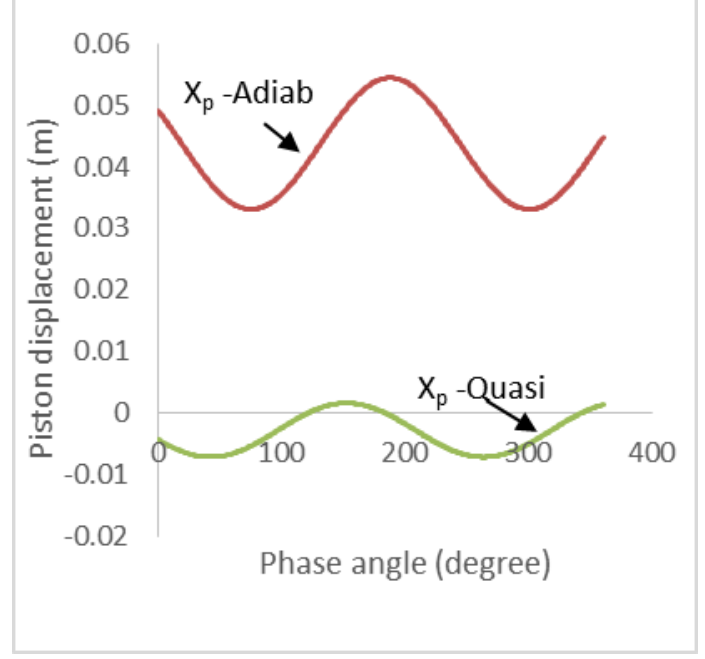

Figure 4. Piston positions against phase angle

The displacement of the displacer and piston amplitudes for the adiabatic and Quasi model against phase angle is presented in Fig.3, and Fig. 4. The displacer of the adiabatic model exhibited maximum displacement of $0.094 \mathrm{~m}$ at phase angle of $163^{\circ}$, while the displacer of the Quasi steady model exhibited maximum displacement of $0.002 \mathrm{~m}$ at $116^{\circ}$. This is due to the effect of the working gas pressure on the displacers, which also indicates position of the displacer at the top dead centre in the cylinder. In Fig. 4, the piston in the adiabatic model exhibited maximum displacement of $0.054 \mathrm{~m}$ at phase angle of $186^{\circ}$, while the piston in the Quasi steady model exhibited maximum displacement of $0.001 \mathrm{~m}$ at $154^{\circ}$. The displacer and piston positions in the adiabatic model shows a considerable margin to the amplitudes of the Quasi steady model of the FPSE. This is due to the pressure function calculation in the numerical model and the effect of the damping load and spring stiffness on the oscillatory motions of the displacer and piston respectively in the two models. It can also be observed that the adiabatic models have an average piston amplitude of $0.03 \mathrm{~m}$ and displacer amplitude of $0.02 \mathrm{~m}$. While the Quasi model have an average piston and displacer amplitude of $0.003 \mathrm{~m}$ and $0.006 \mathrm{~m}$. The variation is due to the magnitude of the working gas pressure exerted on the piston and displacer.

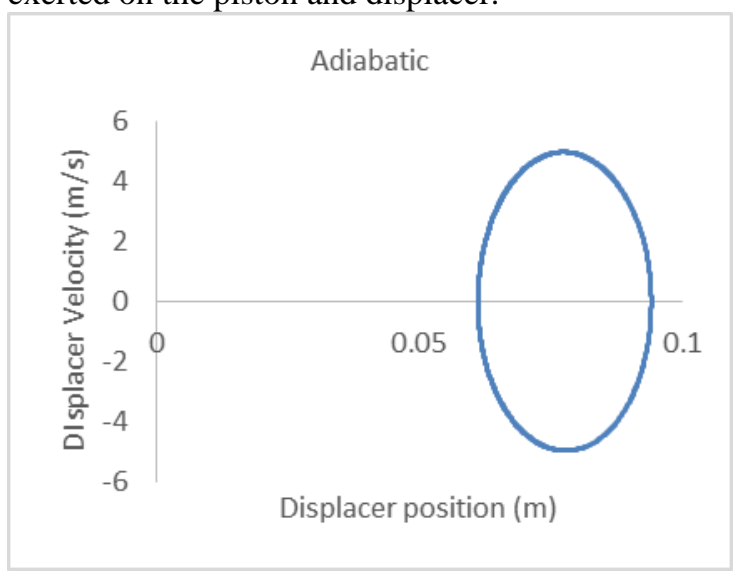

Figure 5. Displacer velocity against displacer position in adiabatic model 


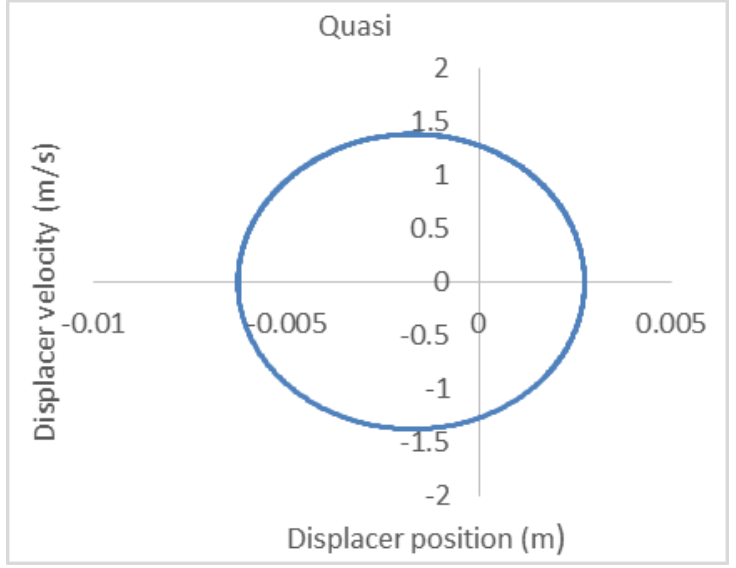

Fig 6. Displacer velocity against displacer position in the Quasi model.

Fig. 5 and Fig. 6, show the velocity of the displacer against the position of the displacer during engine operation, this represents the stability of the two models. It can be observed they form an ellipse each and do not overlap. This is also observed in the results presented in [6] and [10] on the stability check of the operation of the FPSE.

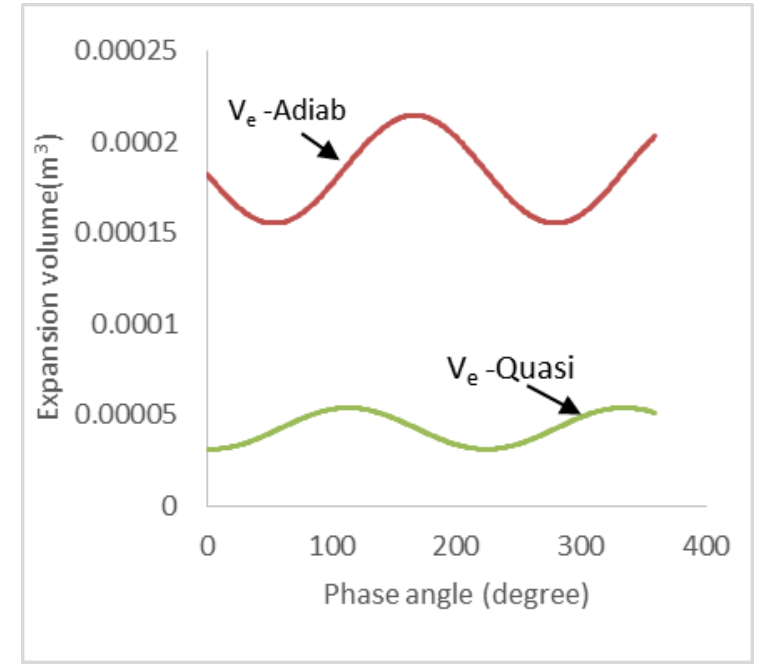

Figure 7. Expansion volume against phase angle

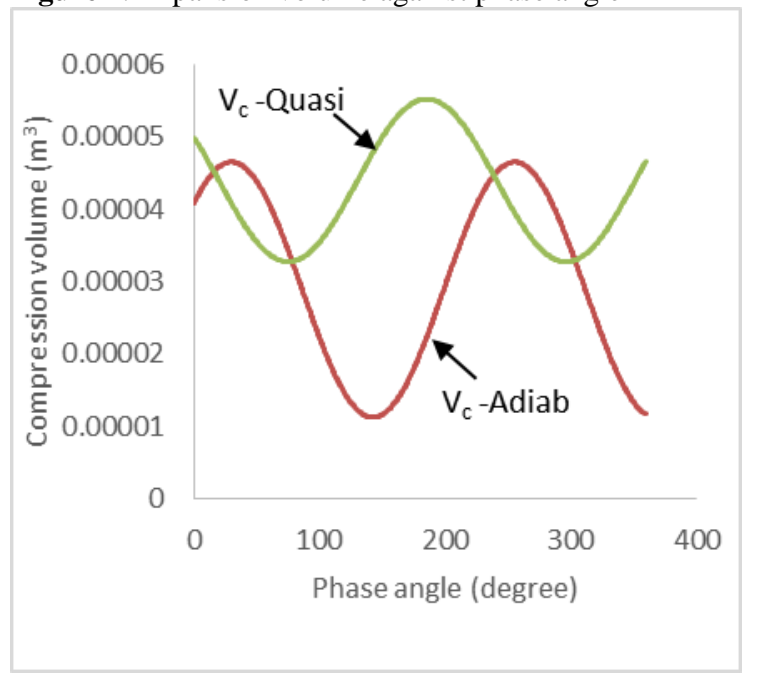

Figure 8. Compression volume against phase angle
The volumes of the working fluid in the expansion and compression spaces against phase angle for the adiabatic and Quasi steady models are illustrated in Fig. 7, and Fig. 8. The adiabatic model exhibited a higher volume difference compared to the Quasi steady model. The higher volume difference in the work spaces can relatively increase or decrease the output power of the FPSE. The adiabatic model predicted a lower output power compared to the Quasi model due to the volume difference in the work spaces. This is as a result of the average pressure and temperature over a complete cycle.

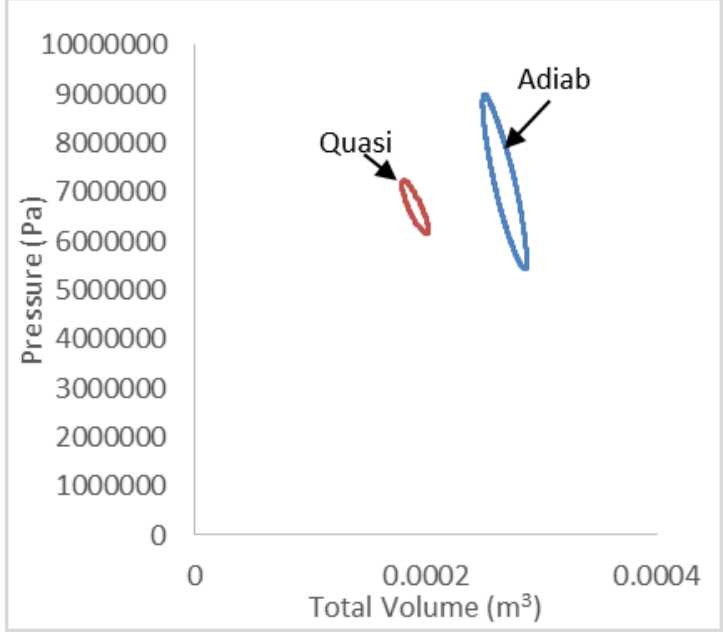

Figure 9. Pressure to Volume diagram

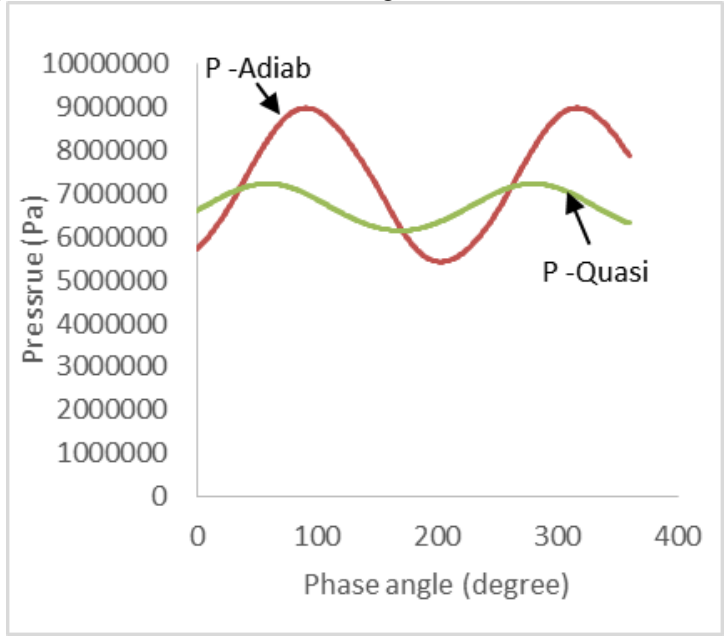

Figure 10. Pressure against phase angle

Fig. 9, represents the pressure to volume diagram of the two models in this study. They present identical elliptical shapes to the ideal Stirling cycle, but the area around the curvature indicates the dead volume not put to work in the expansion and compression spaces. The P-V diagram in the adiabatic and Quasi models have an average pressure of 70bar. This is due to the limited flexibility of the model and the pressure calculation in the numerical simulation. The adiabatic and Quasi steady models presented a more accurate prediction of the FPSE in the output power generated. Fig. 10, shows the pressure variation in the models against phase angle. The adiabatic model exhibited a higher pressure of 89.6 bar at $91^{\circ}$ phase angle compared to the Quasi model that 
exhibited the maximum pressure of 72.3 bar at $65^{\circ}$ phase angle. This is due to the temperature variation, volumes of the work spaces and the mass of the working fluid and gas constant. The consideration of thermal losses and pressure drop in pressure calculation of the Quasi model make a significant difference in the output performance of the models, as this is the major reason for the difference in model prediction. While in the adiabatic model, there was no account for the losses in the system, except the pressure was a function of the piston and displacer dynamics and temperature variation in the workspaces over a complete cycle.

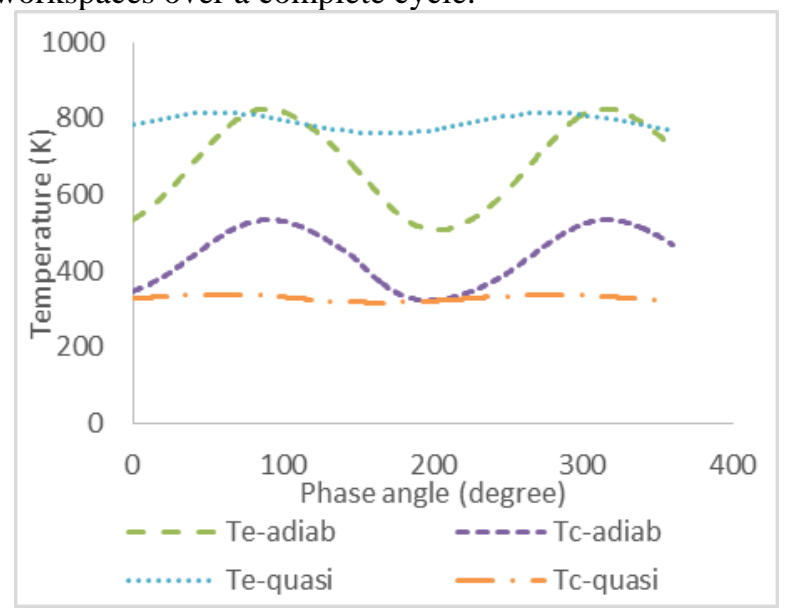

Figure 11. Expansion and compression space temperatures against phase angle

The comparison of the temperature in the expansion and compression spaces in the two models is presented in Fig. 11. In the adiabatic and Quasi steady model, the temperature in the work spaces vary with time in accordance to the assumptions relating to the real time approach of the FPSE. This gives a more accurate prediction of the engine performance. The start points of the temperature varies slightly in the two models due to different cycles each achieves steady state. The criteria for steady state condition checking for the adiabatic and Quasi model was determined by the expansion and compression space temperatures once the value at the beginning of the cycle is the same as the value at the end of the cycle, similar to the condition stated by Urieli and Berchowits [1].

Table 2. Comparison of the output power and efficiency of the models with experiment

\begin{tabular}{|l|l|l|l|}
\hline Output & Experiment & Adiabatic & Quasi \\
\hline $\begin{array}{l}\text { Output power } \\
\text { (W) }\end{array}$ & 1000 & 862 & 997 \\
\hline $\begin{array}{l}\text { Amplitude } \\
\text { ratio }\end{array}$ & 1.06 & 1.76 & 1.01 \\
\hline $\begin{array}{l}\text { Frequency } \\
(\mathrm{Hz})\end{array}$ & 30 & 30 & 30 \\
\hline
\end{tabular}

The difference in the output results of the two models of the FPSE is as a result of the thermal losses pressure drops and influence of the dampers and spring stiffness on the steady state operation of the engine. It can be observed in Table 2, that the Quasi steady state model predicted the closest result to the experimental output. The adiabatic model exhibited a lower value compared to the experimental output power due to the adiabatic condition of the expansion and compression work spaces and there was a slight difference in the displacer damping constant so as to achieve the steady state operation, during simulation at exact damping constant value of 35.34 ms-1 there was no convergence and the computation was altered after few completed cycles. The closest in output result to the experimental value is the Quasi steady state model. This model took into consideration the thermal losses and pressure drops and regenerator effectiveness. The temperature of the work spaces and the heat exchangers changes with time over the cycle similar to real time operation of the FPSE. Hence, the Quasi model predicted the most accurate result. Investigating the accuracy of the different models of the FPSE, It can be observed that the Quasi steady model predicted a power output of $997 \mathrm{~W}$, which is the most accurate result in comparison to the $1000 \mathrm{~W}$ of the RE-1000 FPSE experimental output. The adiabatic model predicted a power output of $862 \mathrm{~W}$ which is not much different from the experimental output. The difference is due to the adiabatic condition of the simulation and the assumptions for the temperature in the expansion and compression spaces. The temperatures in the heat exchangers were assumed to be constant, hence the less accurate prediction of the output performance of the model.

\subsection{Parametric sensitivity analysis}

The influence of some parameters on the output power of the FPSE is presented and discussed in Tables 3 to Table 5 .

Table 3. The effects of damping load on the engine performance

\begin{tabular}{|l|l|l|l|}
\hline $\begin{array}{l}\text { Damping load of } \\
\text { piston }\end{array}$ & $\begin{array}{l}\text { Damping load } \\
\text { of displacer }\end{array}$ & $\begin{array}{l}\text { Power } \\
\text { output } \\
\text { (Adiab) (W) }\end{array}$ & $\begin{array}{l}\text { Power output } \\
\text { (Quasi) (W) }\end{array}$ \\
\hline 465 & 35.34 & 862 & 997 \\
\hline 470 & 45 & 884 & 1025 \\
\hline 480 & 55 & 925 & 1076 \\
\hline 490 & 65 & 973 & 1134 \\
\hline
\end{tabular}

Table 4. The effects of spring stiffness on the engine performance

\begin{tabular}{|l|l|l|l|}
\hline $\begin{array}{l}\text { Spring } \\
\text { stiffness } \\
\text { (piston) }\end{array}$ & $\begin{array}{l}\text { Spring stiffness } \\
\text { (displacer) }\end{array}$ & $\begin{array}{l}\text { Power } \\
\text { output } \\
\text { (Adiab) }(\mathbf{W})\end{array}$ & $\begin{array}{l}\text { Power output } \\
\text { (Quasi) (W) }\end{array}$ \\
\hline 297000 & 25000 & 862 & 997 \\
\hline 300000 & 30000 & 785 & 932 \\
\hline
\end{tabular}




\begin{tabular}{|l|l|l|l|}
\hline 350000 & 35000 & 733 & 893 \\
\hline 400000 & 40000 & 691 & 825 \\
\hline
\end{tabular}

Table 5. The effects of piston and displacer masses on the engine performance

\begin{tabular}{|l|l|l|l|}
\hline $\begin{array}{l}\text { Mass of } \\
\text { Piston }\end{array}$ & Mass of displacer & $\begin{array}{l}\text { Power } \\
\text { output } \\
\text { (Adiab) }(\mathbf{W})\end{array}$ & $\begin{array}{l}\text { Power output } \\
\text { (Quasi) (W) }\end{array}$ \\
\hline 6.2 & 0.426 & 862 & 997 \\
\hline 7.2 & 0.5 & 954 & 1121 \\
\hline 8.2 & 0.6 & 1540 & 1732 \\
\hline 9.2 & 0.7 & 2265 & 2498 \\
\hline
\end{tabular}

The parametric sensitivity analysis shows the influence of different parameters on the power output of the free piston Stirling engine. Table 3 shows the effect of the damping load on the engine output. It can be observed that the increase in the damping load of the piston and displacer increases the power output of the engine, this is due to the increase in the load on the masses of the piston and displacer which produces more work in the work spaces. The dampers are a form of additional load to the displacer and piston which is expected to add more work and increase the output power of the FPSE. In Table 4, the effects of spring stiffness on the power output of the engine is presented. It can be observed that the increase in the stiffness if the springs reduces the output power of the engine considerably. This is due to the limitation the stiffness result to on the allowance it gives to the displacer and piston during oscillation, this advertently reduces the displacement and velocity of the moving elements and thereby reducing the amount of the swept volume of gas converted to work in the expansion and compression spaces. The spring and damping constants are major determining factors for the stability and steady operation of the FPSE. The angular frequency depends solely on the mass and spring stiffness of moving elements. Due to complexity of the relation of these parameters to the motion of the piston and displacer in contrast to the crank mechanism of the kinematic Stirling engines, accurate determination of these parameters are required. In the Quasi steady model developed in this study, the damping load is calculated every time step with other parameters in the cycle as this is affected by the pressure variation, temperature change and volume difference in the work spaces. The accurate damping load is determined at the time step when the steady state of the FPSE is achieved. The spring stiffness is to add stability to the oscillatory motions of the moving elements. But on the contrary an adverse effect can be observed due to the increase in these factors and could cause instability in the engine. Hence, an accurate definition of these parameters is required for a steady operation of the engine. Table 5 shows the effects of piston and displacer masses on the engine's output power. It can be observed that the increase in the masses of the piston and displacer increases the output power of the engine respectively. This is due to increase in the swept volume of the working gas, and the increase of the forces exerted on the masses of piston and displacer which increases their acceleration. Therefore, from the observation of the effects of variation in the free piston Stirling engine's parameter, this indicates that careful consideration should be given to their selection during design stage of the engine.

\section{Conclusion}

In this present study numerical analysis is carried out on the adiabatic and Quasi models of the free piston Stirling engine in order to predict the satisfactory performance of the models and compare their outputs. The following conclusions are presented:

-The two models are developed and their output results analysed and the Quasi steady model predicted the most accurate results in terms of amplitude ratio and power output.

-Detailed and accurate analysis of the relation between the dynamic and thermodynamic characteristics of the FPSE is essential in order to understand better the performance characteristics of the engine.

-Parametric sensitivity analysis performed on the numerical models exhibited a considerable effect on the output power of the FPSE.

Therefore it can be concluded from this study that advanced algorithm and detailed description of the working condition of the FPSE is required in order to predict a satisfactory output performance of the engine.

\section{NOMENCLATURE}

$A_{d} \quad$ Cross sectional area of the piston $\left(\mathrm{m}^{2}\right)$

$A_{p} \quad$ Cross sectional area of the displacer $\left(\mathrm{m}^{2}\right)$

$\mathrm{C}_{\mathrm{ap}} \quad$ Specific heat at constant pressure $(\mathrm{J} / \mathrm{kgK})$

$\mathrm{C}_{\mathrm{av}} \quad$ Specific heat at constant volume $(\mathrm{J} / \mathrm{kgK})$

k Thermal conductivity (W/mk)

$\mathrm{m}_{\mathrm{d}} \quad$ Mass of the displacer $(\mathrm{kg})$

$\mathrm{m}_{\mathrm{p}} \quad$ Mass of the piston $(\mathrm{kg})$

$\mathrm{T}_{\mathrm{k}} \quad$ Temperature of the cooler $(\mathrm{K})$

$\mathrm{T}_{\mathrm{r}} \quad$ Temperature of the regenerator $(\mathrm{K})$

$\mathrm{T}_{\mathrm{h}} \quad$ Temperature of the heater $(\mathrm{K})$

$\mathrm{T}_{\mathrm{ck}} \quad$ Temperature of the compression space to cooler

(K)

$T_{\text {he }} \quad$ Temperature of the heater to expansion space $(\mathrm{K})$

$\mathrm{T}_{\mathrm{rh}} \quad$ Temperature of the regenerator to heater $(\mathrm{K})$

$\mathrm{T}_{\mathrm{kr}} \quad$ Temperature of the cooler to regenerator $(\mathrm{K})$

$V_{b} \quad$ Bounce space volume $\left(\mathrm{m}^{\mathrm{a}}\right)$

$V_{r} \quad$ Volume of the regenerator $\left(\mathrm{m}^{\mathrm{a}}\right)$

$V_{h} \quad$ Volume of the heater $\left(\mathrm{m}^{\mathrm{a}}\right)$

$V_{k} \quad$ Volume of the cooler $\left(\mathrm{m}^{\mathrm{a}}\right)$

$V_{\text {cle }} \quad$ Compression space clearance volume $\left(\mathrm{m}^{\mathrm{a}}\right)$

$V_{\text {cle }} \quad$ Expansion space clearance volume $\left(\mathrm{m}^{\mathrm{a}}\right)$

$\mathrm{x}_{\mathrm{p}} \quad$ Displacement of piston $(\mathrm{m})$

$\dot{\mathrm{x}}_{\mathrm{p}} \quad$ Velocity of piston $(\mathrm{m} / \mathrm{s})$ 


$\begin{array}{ll}\overline{\mathrm{X}}_{\mathrm{p}} & \text { Acceleration of piston }\left(\mathrm{m} / \mathrm{s}^{2}\right) \\ \mathrm{x}_{\mathrm{d}} & \text { Displacement of displacer }(\mathrm{m}) \\ \tilde{\mathrm{x}}_{\mathrm{d}} & \text { Velocity of displacer }(\mathrm{m} / \mathrm{s}) \\ \overline{\mathrm{x}}_{\mathrm{d}} & \text { Acceleration of displacer }\left(\mathrm{m} / \mathrm{s}^{2}\right) \\ \mathrm{R} & \text { Gas constant value } \\ \mathrm{Q} & \text { Heat transfer rate }(\mathrm{W}) \\ \mathrm{P}_{\mathrm{e}} & \text { Pressure in expansion space } \\ \mathrm{P}_{\mathrm{c}} & \text { Pressure in compression space } \\ \text { FPSE } & \text { Free piston Stirling engine } \\ \text { Adiab } & \text { Adiabatic }\end{array}$

\section{References}

1. Urieli I. and Berchowitz, D. "Stirling Cycle Engine Analysis," Altern. Sources Energy, pp. 71-71, 1984.

2. Formosa F., and Frechette L.G., "Scaling laws for free piston Stirling engine design: Benefits and challenges of miniaturization," Energy, vol. 57, pp. 796-808, 2013.

3. Bégota S., Layes G., Lanzetta F., and Nika P., "Stability analysis of free piston Stirling engines," Phys. Energy Transf. Convers. Storage, vol. 61, no. Eur. Phys. J. Appl. Phys., 2013.

4. Riofrio J. A., Al-Dakkan K., Hofacker M. E, and Barth E. J., "Control-based design of free-piston stirling engines," Proc. Am. Control Conf., pp. 1533 1538, 2008.

5. Sowale A. "Modelling and Optimisation of a Free Piston Stirling Engine for Micro-CHP Applications," Doctoral thesis Northumbria University; 2015.

6. Jia B., Tian G, Feng H., Zuo Z, and Roskilly A. P, "An experimental investigation into the starting process of free-piston engine generator," Appl. Energy, vol. 157, pp. 798-804, 2015

7. Yang Q, Luo E, Dai W, and Yu G, "Thermoacoustic model of a modified free piston Stirling engine with a thermal buffer tube," Appl. Energy, vol. 90, pp. 266-270, 2012.

8. Kim J., Choongsik B, and Kim G., "Simulation on the effect of the combustion parameters on the piston dynamics and engine performance using the Wiebe function in a free piston engine," Appl. Energy, vol. 107, pp. 446-455, 2013.

9. Walker G., Senft J.R. (1985) Free-Piston Stirling Engines. In: Free Piston Stirling Engines. Lecture Notes in Engineering, vol 12. Springer, Berlin, Heidelberg.

10. Rogdakis E.D, Bormpilas N.A, and.Koniakos I.K, "A thermodynamic study for the optimization of stable operation of free piston Stirling engines," Energy Convers. Manag., vol. 45, pp. 575-593, 2004. 